\title{
TEACHER EMPOWERMENT IN APPLYING LEARNING PRINCIPLES TO DEAF STUDENTS IN ELEMENTARY SCHOOL, SUKAMAKMUR DISTRICT
}

\author{
Murni Winarsih, Totok Bintoro \\ Special Education Study Program, Faculty of Education Science, Universitas Negeri \\ Jakarta \\ murniwinarsih.tgsmhs@gmail.com
}

\begin{abstract}
The purpose of this community service activity is to provide knowledge and skills to elementary school teachers in applying the principles of learning for deaf students in inclusive education institutions. Insights into the knowledge and skills provided about the basic concepts of inclusive education, the introduction of ABK and its characteristics, identification of deaf $\mathrm{ABK}$, the principles of deaf $\mathrm{ABK}$ learning and assessment of learning outcomes for deaf ABK. This activity was carried out in the form of Technical Guidance (Bimtek) for elementary school teachers. The topic was the Socialization of Children with Special Needs specifically Deafness in the Fostered area of Sukamakmur District, Bogor. This community service is carried out for 2 (two) days through training methods, lectures, interactive discussions, $\mathrm{Q}$ and A with speakers coming from lecturers of Special Education (PKh) study programs. This P2M activity was followed enthusiastically by 50 teachers from schools located in Sukamakmur District. The results obtained from this P2M activity are changes in the mindset of teachers in looking at $\mathrm{ABK}$ and addressing inclusive education. In addition, teachers also have skills in identifying deaf $\mathrm{ABK}$ and learning by using specific principles for deaf ABK. It is expected that this P2M activity can be continued in the following year with more diverse material and wider target groups.
\end{abstract}

Keywords: Teacher empowerement, learning principles, deaf students, elementary school

\begin{abstract}
Abstrak
Tujuan kegiatan pengabdian kepada masyarakat ini adalah untuk memberikan bekal pengetahuan dan keterampilan kepada guru sekolah dasar dalam menerapkan prinsip-prinsip pembelajaran untuk siswa tunarungu yang berada di sekolah penyelengagara pendidikan inklusif. Wawasan pengetahuan dan keterampilan yang diberikan tentang konsep dasar pendidikan inklusif, pengenalan ABK dan karakteristiknya, identifikasi $A B K$ tunarungu, prinsip-prinsip pembelajaran $A B K$ tunarungu dan penilaian hasil belajar bagi ABK tunarungu. Kegiatan ini dilakukan dalam bentuk Bimbingan Teknis (Bimtek) untuk guru sekolah dasar tentang Sosialisasi Anak Berkebutuhan Khusus Tunarungu Di Gugus Wilayah Binaan Kecamatan Sukamakmur Bogor. Pengabdian masyarakat ini dilaksanakan selama 2 (dua) hari dengan metode pelatihan, melalui ceramah, diskusi dan tanya jawab interaktif, dengan nara sumber yaitu dosen-dosen program studi Pendidikan Khusus (PKh). Kegiatan P2M ini diikuti dengan antusias dan penuh semangat oleh 50 orang guru yang berasal dari sekolah-sekolah yang berada di Kecamatan Sukamakmur. Hasil yang diperoleh dari kegiatan P2M ini adalah perubahan mindset para guru dalam memandang $A B K$ dan menyikapi pendidikan inklusif. Selain itu guru-guru juga memiliki keterampilan dalam mengidentifikasi ABK tunarungu serta melakukan pembelajaran dengan menggunakan prinsip-prisip khusus bagi ABK tunarungu. Diharapkan kegiatan P2M ini dapat dilanjutkan pada tahun berikutnya dengan materi yang lebih beragam dan kelompok sasaran yang lebih luas lagi.
\end{abstract}

Kata kunci: Pemberdayaan guru, prinsip-prinsip pembelajaran, siswa tunarungu, sekolah dasar 
DOI: https://doi.org/10.21009/sarwahita.151.03

P-ISSN: 0216-7484

E-ISSN: 2597-8926

\section{PENDAHULUAN}

\section{A. Analisis Situasi}

Dalam rangka meningkatkan sumber daya manusia, pendidikan menempati posisi yang amat strategis. Kualitas dan kuantitas pendidikan yang ada akan menentukan ketersediaan sumber daya manusia. Sumber daya manusia yang berkualitas, hanya akan lahir dari pendidikan yang berkualitas. Kebijakan pemerintah dalam bidang pemerataan misalnya, dimaksudkan agar semua warga negara Indonesia memperoleh kesempatan yang sama dalam mengenyam dan mengikuti pendidikan yang berkualitas. Idealnya setiap warga negara memiliki kesempatan yang sama dalam mendapatkan pendidikan, baik bagi anak yang normal maupun anak yang berkebutuhan khusus.

Anak berkebutuhan khusus yaitu anak yang secara signifikan mengalami kelainan atau penyimpangan (fisik, mental-intelektual, sosial, emosional) dalam proses pertumbuhan atau perkembangannya dibandingkan dengan anak-anak lain seusianya sehingga mereka memerlukan pelayanan pendidikan khusus. Dengan demikian meskipun seorang anak mengalami kelainan atau penyimpangan tertentu, tetapi kelainan atau penyimpangan tersebut tidak signifikan sehingga mereka tidak memerlukan pelayanan pendidikan khusus anak tersebut bukan anak berkebutuhan khusus.

Kenyataan sekarang menandakan bahwa masih banyak anak berkebuthan

khusus yang belum memperoleh haknya mendapatkan pendidikan. Bersamaan dengan upaya meningkatnya jumlah anak berkebutuhan khusus mengikuti pendidikan, aspek kualitas layanan pendidikan pun harus selalu ditingkatkan sebagai bentuk perwujudan tanggung jawab kita terhadap pendidikan di Indonesia.

Berdasarkan hasil FGD (Forum Group Discuss) yang dilakukan oleh tim dosen FIP (Fakultas Ilmu Pendidikan) pada hari Rabu tanggal 11 April 2018 di Kecamatan Sukamakmur Bogor dengan mengusung tema "Fakultas Ilmu Pendidikan Dalam Pemetaan Kebutuhan Masyarakat" melalui Kelompok Diskusi Terpimpin yang dihadiri oleh para pengawas, kepala sekolah, dan guru dari jenjang Pendidikan Anak Usia Dini, Sekolah Dasar, Sekolah Menemgah Pertama, Sekolah menengah Atas dan SMK juga Madrasah dan Ibtidaiyah, diperoleh data bahwa Kecamatan Sukamakmur terdiri dari sepuluh desa terdapat lima gugus wilayah binaan yaitu gugus wilayah Sukamakmur, Pabuaran, Cimenyan, Sirnajaya dan Sukawangi. Pada Jenjang Pendidikan Sekolah Dasar dari tiap-tiap atau masing-masing gugus terdiri dari lima Sekolah Dasar Negeri $(\mathrm{SDN})$. Terdapat 30 SD Negeri dan $17 \mathrm{SD}$ Swasta. 30 SDN dibagi menjadi 5 gugus KKG. Kelima gugus tersebut adalah Sukamakmur sebagai koordinatornya yaitu Bapak Deni ; Pabuaran sebagai koordinatornya yaitu Bapak 
DOI: https://doi.org/10.21009/sarwahita.151.03

P-ISSN: 0216-7484

E-ISSN: 2597-8926

Berdasarkan hasil diskusi dengan para peserta Kepala Sekolah jenjang SD dan Ketua Gugus Wilayah Binaan Kecamatan Sukamakmur, diperoleh data bahwa sekolah diwajibkan menerima anak yang ingin bersekolah dalam kondisi apapun meskipun anak tersebut termasuk dalam kelompok anak berkebutuhan khusus. Seperti diketahui bahwa di Gugus Wilayah Binaan Kecamatan Sukamakmur Bogor tidak ada SDN yang menyelenggarakan Pendidikan Inklusi. Ironisnya di SDN Gugus binaan wilayah Kecamatan Sukamakmur tidak ada guru bahkan kepala sekolah yang mengenal atau memiliki pengetahuan tentang anak berkebutuhan khusus. Dari pihak Pemerintah Daerah tidak pernah menyelenggarakan kegiatan ilmiah seperti seminar atau workshop atau lain-lain tentang sosialisasi anak berkebutuhan khusus untuk meningkatkan pengetahuan guru atau kepala sekolah tentang anak berkebutuhan khusus. Terdapat beberapa ABK yang belajar di beberapa SD, padahal SD tersebut bukan SD Inklusif. Tidak diadakan layanan khusus dikarenakan keterbatasan pemahaman guru tentang ABK. Diperoleh data dari kepala sekolah SDN bahwa dalam masing-masing SDN memiliki Anak Berkebutuhan Khusus (ABK) hampir di setiap kelasn terdapat ABK.

Adapun masing-masing sekolah memiliki klasifikasi Anak Berkebutuhan Khusus (ABK) yang bersifat heterogen yaitu terdiri dari siswa yang mengalami
Gangguan Wicara, Gangguan Intelektual, Gangguan Fisik Motorik, Lambat Belajar, Berbakat dan Kesulitan Belajar. Berdasarkan faktor guru yang tidak mengenal siswanya yang berkebutuhan khusus maka dalam membelajarkan Anak Berkebutuhan Khusus (ABK), guru sesuai dengan keinginan sendiri karena guru kesulitan dalam memberikan pelayanan pendidikan yang sesuai dengan kondisi dan kebutuhan Anak Berkebutuhan Khusus (ABK). Hal tersebut menjadi perhatian yang lebih dalam melakukan pembelajaran di kelas, agar setiap siswa mendapatkan pembelajaran yang sesuai dengan kemampuannya.

Guru SD merupakan guru yang memberikan layanan pendidikan kepada siswa jenjang pendidikan dasar. Untuk melakukan tugasnya secara baik sesuai dengan profesi yang dimilikinya, guru perlu menguasai berbagai hak sebagai kompetensi yang dimilikinya. Oleh karena itu guru dituntut agar dalam pelayanan pendidikan diharapkan mencapai tujuan kemandirian kepada siswanya secara optimal.

Untuk guru di SDN Kecamatan Sukamakmur Bogor khususnya gugus wilayah binaan Sukamakmur juga dituntut memberikan pelayanan pendidikan kepada siswa yang berkebutuhan khusus yang ada di kelasnya meskipun guru tidak dibekali pengetahuan tentang anak berkebutuhan khusus. Hal tersebut berdampak pada siswa berkebutuhan khusus tidak memperoleh hak pendidikan yang layak. Oleh karena itu diperlukan pendampingan 
DOI: https://doi.org/10.21009/sarwahita.151.03

P-ISSN: 0216-7484

E-ISSN: 2597-8926

guru SD untuk mengoptimalkan kemampuan yang ada pada Anak Berkebutuhan Khusus (ABK). Secara terinci masalah yang dihadapi guru sebagai berikut:

1. Guru SD belum semua memahami tentang konsep Anak Berkebutuhan Khusus (ABK) tunarungu

2. Guru SD belum dapat mengidentifikasi tentang cara mengenali Anak Berkebutuhan Khusus (ABK) tunarungu.

3. Guru SD belum memahami cara memberikan layanan pendidikan yang sesuai dengan kebutuhan Anak Berkebutuhan Khusus (ABK) tunarungu.

4. Guru SD belum memahami cara melakukan evaluasi pembelajaran untuk Anak Berkebutuhan Khusus (ABK) tunarungu.

5. Guru SD perlu meningkatkan kompetensi pedagogik dalam memberikan layanan pendidikan yang sesuai dengan kebutuhan Anak Berkebutuhan Khusus (ABK) tunarungu.

\section{B. Perumusan Masalah}

Bagaimana meningkatkan kemampuan guru dalam melakukan pembelajaran kepada Anak Berkebutuhan Khusus (ABK) tunarungu di Sekolah Dasar Negeri (SDN) di Kecamatan Sukamakmur?

\section{Tujuan Kegiatan}

Kegiatan pengabdian masyarakat ini adalah untuk memberikan bekal pengetahuan dan keterampilan kepada guru sekolah dasar dalam menerapkan prinsip-prinsip pembelajaran untuk siswa tunarungu yang berada di sekolah penyelengagara pendidikan inklusif.

\section{Manfaat Kegiatan}

Manfaat kegiatan pengabdian masyarakat ini adalah agar guru di SD Kecamatan Sukamakmur Bogor khususnya gugus wilayah binaan Sukamakmur dapat memberikan pelayanan pendidikan kepada Anak Berkebutuhan Khusus (ABK) yang ada di kelasnya khususnya untuk siswa tunarungu. Selain itu diharapkan guru SD di Kecamatan Sukamakmur dapat mengoptimalkan kemampuan yang ada pada Anak Berkebutuhan Khusus (ABK) tunarungu dalam proses pembelajaran dengan menggunakan prinsip-prinsip khusus tunarungu dalam setting kelas inklusi, memberikan wawasan pengetahuan dan keterampilan yang diberikan tentang konsep dasar pendidikan inklusif, pengenalan $\mathrm{ABK}$ dan karakteristiknya, identifikasi ABK tunarungu, prinsip-prinsip pembelajaran ABK tunarungu dan penilaian hasil belajar bagi ABK tunarungu.

Berdasarkan kajian literatur anak berkebutuhan khusus atau anak luar biasa adalah anak yang dalam proses pertumbuhan dan perkembangannya secara signifikan (bermakna) mengalami kelainan/penyimpangan/hambatan baik secara fisik, mental intelektual, sosial dan emosional, sehingga mereka memerlukan pelayanan pendidikan khusus. 
DOI: https://doi.org/10.21009/sarwahita.151.03

P-ISSN: 0216-7484

E-ISSN: 2597-8926

Dari batasan tersebut dapat berarti bahwa meskipun seorang anak mengalami kelainan /penyimpangan/ hambatan tertentu, tetapi kelainan /penyimpangan/ hambatan tersebut tidak signifikan sehingga mereka tidak memerlukan pelayanan pendidikan khusus, maka anak tersebut bukan termasuk anak berkebutuhan khusus.

Jika diklasifikasikan anak berkebutuhan khusus ada bermacammacam tergantung dari sudut pandang yang digunakan, yaitu anak tunanetra, tunarungu, tunagrahita, tunadaksa, dan tunalaras. Pada kegiatan pengabdian kepada masyarakat ini dibatasi pada Anak Berkebutuhan Khusus (ABK) tunarungu.

Sekolah Dasar Penyelenggara

Pendidikan Inklusif merupakan perkembangan terbaru model pendidikan bagi anak berkebutuhan khusus yang secara formal ditegaskan dalam pernyataan Salamanca pada Konferensi Dunia tentang Pendidikan Berkelainan yang dideklarasikan pada bulan Juni 1994, mengemukakan bahwa "Prinsip mendasar dari pendidikan inklusif adalah selama memungkinkan, semua anak seyogyanya belajar bersama-sama tanpa memandang kesulitan ataupun perbedaan yang mungkin ada pada mereka”.

Kaitannya dengan Pendidikan Inklusif, Stainback (Budiyanto, 2005:18) memberikan batasan yang relatif lebih spesifik dalam konteks seting persekolahannya, yaitu sekolah yang menampung semua siswa di kelas yang sama. Sekolah ini menyediakan program pendidikan yang layak, menantang, tetapi sesuai dengan kemampuan dan kebutuhan setiap siswa, maupun bantuan dan dukungan yang dapat diberikan oleh para guru agar anak-anak berhasil. Lebih dari itu, Sekolah Dasar Penyelenggara Pendidikan Inklusif juga merupakan tempat setiap anak dapat diterima, menjadi bagian dari kelas tersebut, dan saling membantu dengan guru dan teman sebayanya, maupun anggota masyarakat lain agar kebutuhan individualnya dapat terpenuhi.

Salah satu karakteristik terpenting dari sekolah dasar penyelenggara pendidikan inklusif adalah satu komunitas yang kohesif, menerima dan responsive terhadap kebutuhan individual siswa. Untuk itu, Sapon-Shevin (Sunardi: 2002) mengemukakan lima profil pembelajaran di Sekolah Dasar Penyelenggara Pendidikan Inklusif, yaitu :

1. Pendidikan Inklusif berarti menciptakan dan menjaga komunitas kelas yang hangat, menerima keanekragaman, dan menghargai perbedaan.

2. Mengajar kelas yang hetorogen memerlukan perubahan pelaksanaan kurikulum secara mendasar.

3. Pendidikan Inklusif berarti menyiapkan dan mendorong guru untuk mengajar secara interaktif.

4. Pendidikan Inklusif berarti penyediaan dorongan bagi guru dan kelasnya secara terus menerus dan penghapusan hambatan yang berkaitan dengan isolasi profesi. 
DOI: https://doi.org/10.21009/sarwahita.151.03

P-ISSN: 0216-7484

E-ISSN: 2597-8926

5. Dengan pendidikan inklusif berarti melibatkan orang tua secara bermakna dalam proses perencanaan begitu pula dengan keterlibatan masyarakat sekitarnya.

Hal ini membawa implikasi pada ketercapaian indikator keberhasilan pendidikan inklusif pada suatu sekolah yaitu adanya saling menghargai, toleransi, menjadi bagian suatu masyarakat, diberikan kesempatan untuk mengembangkan keterampilan dan bakat, saling membantu, belajar dari satu sama lain, dan membantu orang untuk menolong dirinya sendiri dan masyarakatnya.

\section{METODE PELAKSANAAN}

\section{A. Metode Pemecahan Masalah}

Kegiatan pengabdian masyarakat ini dilakukan melalui bimbingan teknik (Bimtek) dengan metode pelatihan tentang pembelajaran kepada Anak Berkebutuhan Khusus (ABK) dalam setting pendidikan inklusif, metode lain yang digunakan adalah metode ceramah, diskusi, simulasi serta tanya jawab interaktif kepada para guru di sekolah dasar wilayah binaan kecamatan Sukamakmur sebagai peserta pelatihan.

Materi yang diberikan dalam kegiatan ini adalah berupa pengetahuan dan keterampilan tentang konsep dasar pendidikan inklusi, konsep dasar ABK, konsep dasar $\mathrm{ABK}$ tunarungu, cara mengidentifikasi $\mathrm{ABK}$ tunarungu, prinsipprinsip pembelajaran bagi $A B K$ tunarungu, dan model pengembangan kompetensi pedagogik bagi guru di

sekolah dasar dalam memberikan layanan pembelajaran kepada siswa tunarungu.

\section{B. Kerangka Pemecahan Masalah}

Kegiatan ini melibatkan lembaga Pengabdian Pada Masyarakat Fakultas Ilmu Pendidikan Universitas Negeri Jakarta sebagai lembaga yang memberikan kebijakan terkait program pengabdian masyarakat yang dilaksanakan oleh setiap dosen yang berada di Fakultas Ilmu Pendidikan (FIP), Program Studi Pendidikan Khusus (PKh) sebagai pelaksana yang memberikan pelatihan kepada guru-guru, beberapa sekolah dasar di Wilayah Binaan Kecamatan Sukamakmur Bogor yang sekaligus sebagai lokasi tempat pelaksanaan kegiatan pengabdian pada masyarakat ini. Evaluasi dalam kegiatan pengabdian masayarakat ini adalah evaluasi proses, yaitu sebelum, selama berlangsungnya dan setelah melakukan kegiatan pengabdian masyarakat yaitu dengan tes tertulis dan tes praktik dalam bentuk instrument terkait tentang pengetahuan atau teori konsep dasar ketunarunguan dan prinsip-prinsip pembelajaran, dan secara praktik yaitu penerapan prinsip-prinsip pembelajaran khusus bagi $\mathrm{ABK}$ tunarungu dalam proses pembelajaan secara berkesinambungan. Dengan demikian diharapkan melalui evaluasi yang diberikan dapat diketahui tingkat keberhasilan dalam pelaksanaan kegiatan pengabdian masyarakat ini.

\section{Khalayak Sasaran}


DOI: https://doi.org/10.21009/sarwahita.151.03

P-ISSN: 0216-7484

E-ISSN: 2597-8926

Khalayak sasaran dalam kegiatan pengabdian masyarakat ini adalah guuguru sekolah dasar yang berada di wilayah kecamatan Sukamakmur, yang berjumlah 50 orang. Selama ini guru-guru tersebut belum pernah memperoleh pengetahuan dan keterampilan terkait dengan konsep dasar pendidikan inklusif, pengenalan ABK dan karakteristiknya, identifikasi ABK tunarungu, prinsip-prinsip pembelajaran $\mathrm{ABK}$ tunarungu dan penilaian hasil belajar bagi $\mathrm{ABK}$ tunarungu.

\section{Tempat dan Waktu Pelaksanaan}

Tempat kegiatan pengabdian masyarakat ini dilakukan di Sekolah Dasar Negeri Sukamakmur 02, Bogor Jawa Barat.

Waktu kegiatan pengabdian masyarakat ini dilakukan selama 2 (dua) hari, yaitu pada tanggal 26 dan 27 Juli 2018 serta pendampingan secara berkesinambungan setelah pelaksanaan kegiatan dengan penjadwalan yang telah disepakati.

\section{HASIL DAN PEMBEAHASAN}

\section{A. Hasil Kegiatan}

Kegiatan Bimbingan Teknis Untuk Guru Sekolah Dasar Negeri (SDN) Tentang Bimbingan Teknik Pembelajaran Anak Berkebutuhan Khusus Tunarungu Di Gugus Wilayah Binaan Kecamatan Sukamakmur Bogor, dilaksanakan dalam bentuk pelatihan yang dilakukan selama 2 (dua) hari yaitu pada tanggal 26 dan 27 Juli 2017, yang dilakukan dengan mengikutsertakan guru-guru sebanyak 50 orang, dengan nara sumber dosen-dosen program studi Pendidikan Khusus Fakultas Ilmu Pendidikan Universitas Negeri Jakarta.

Kegiatan pengabdian masyarakat ini diawali dengan pembukaan, pembacaan doa, sambutan perwakilan dari Fakultas Ilmu Pendidikan, kemudian dilanjutkan dengan acara inti yaitu pemberian materi tentang, 1) Konsep Dasar Pendidikan Inklusif, 2) Pengenalan ABK dan Karakteristiknya, 3) Identifikasi ABK Tunarungu, 4) Prinsip-prinsip Pembelajaran ABK Tunarungu di Sekolah Penyelenggara Pendidikan Inklusif dan 5) Model Penilaian untuk ABK di Sekolah Penyelenggara Pendidikan Inklusif.Kegiatan P2M ini berjalan dengan lancar dan tertib, peserta sangat antusias dikarenakan dalam mengikuti Bimtek, dikarenakan para guru belum pernah mengikuti kegiatan seperti ini dan materi yang diberikan juga belum pernah didapatkan, sebelumnya. Selain itu paparan yang diberikan oleh para nara sumber sangat menarik sehingga selama 2 (dua) hari kegiatan para peserta tetap bersemangat mengikutinya. Tanggapan para guru terhadap kegiatan $\mathrm{P} 2 \mathrm{M}$ ini sangat positif dan mereka berkeinginan untuk diadakan secara berkesinambungan dan terprogram bagi semua guru-guru yang belum mengikuti pada kesempatan ini.

\section{B. Pembahasan}

Setelah mengikuti pelatihan selama 2 (dua) pihak mitra sangat 
DOI: https://doi.org/10.21009/sarwahita.151.03

P-ISSN: 0216-7484

E-ISSN: 2597-8926

berterima kasih dan mengharapkan keberlanjutan pelatihan-pelatihan seperti ini dengan materi-materi yang lain dan dapat dilakukan secara berkesinambungan dan terprogram, agar para guru di Kecamatan Sukamakmur lebih berkualitas dan dapat memberikan layanan pembelajaran kepada ABK di sekolah masing-masing sesuai dengan kebutuhan dan karakteristik ABK.

Kegiatan P2M ini dilakukan berdasarkan analisis situasi yaitu kompetensi guru SD di Kecamatan Sukamakmur belum memahami tentang Pendidikan inklusif, belum memahami dan mengenal $\mathrm{ABK}$, belum memahami cara mengidentifikasi ABK tunarungu, belum mampu memberikan layanan pembelajaran kepada ABK tunarungu serta belum memahami cara memebrikan penilaian bagi ABK tunarungu di sekolah penyelenggara pendidikan inklusif. Berdasarkan analisis situasi dan kebutuhan yang diperlukan oleh guru-guru tersebut maka kegiatan BIMTEK ini dilakukan selama 2 (dua) hari.

Pada awal kegiatan kemampuan guru belum menguasai materi-materi yang telah disebutkan di atas, setelah mengikuti BIMTEK selama 2 (dua) hari, terlihat perubahan mindset/ pola pikir dari para guru terhadap pendidikan inklusif, cara memandang $\mathrm{ABK}$, dan berdasarkan pengamatan dan instrument yang diberikan tim pelaksana, para guru sudah memiliki wawasan tentang cara mengidentifikasi $\mathrm{ABK}$ tunarungu serta memiliki wawasan dalam melakukan

pembelajaran dengan prinsip-prinsip khusus untuk ABK tunarungu serta memiliki pengetahuan dalam memberikan penilaian untuk $A B K$ tunarungu di sekolah penyelenggara Pendidikan inklusif.

Berdasarkan hasil capaian kegiatan P2M selama 2 (dua) hari tersebut,maka kegiatan P2M ini menghasilkan capaian yang positif dan sangat bermanfaat bagi mitra sasaran di Kecamatan Sukamakmur. Untuk itu diharapkan adanya kelanjutan program P2M berikutnya dengan materimateri yang lainnya yang masih terkait dengan pendidikan inklusif dan pendidikan khusus dan dengan kelompok sasaran yang lebih luas lagi.

\section{Tindak Lanjut Kegiatan}

Kegiatan P2M yang dilakukan dalam bentuk Bimtek selama 2 (dua) hari ini, berdasarkan capaian yang dihasilkan maka kegiatan ini diharapkan dapat dilanjutkan pada tahun berikutnya dengan kelompok sasaran yang berbeda dengan jumlah peserta yang lebih banyak lagi agar tujuan dari pelaksanaan P2M, khususnya pelaksanaan pendidikan inklusif dapat terwujud segera dan merata keseluruh wilayah Kecamatan Sukamakmur dan sekitarnya.

Namun untuk perluasan dan mengenalkan program-program Fakultas Ilmu Pendidikan (FIP) dan programprogram kegiatan Prodi Pendidikan Khusus (PKh) tidak menutup kemungkinan jika lokasi kegiatan dapat berpindah dan kelompok sasarannya juga berbeda. Hal ini dikarenakan untuk 
DOI: https://doi.org/10.21009/sarwahita.151.03

P-ISSN: 0216-7484

E-ISSN: 2597-8926

kemudahan dan pemerataan serta Selain itu kegiatan ini juga sebagai pengembangan keilmuan di wilayahwilayah lain yang masih membutuhkan pengabdian dari Lembaga P2M FIP UNJ.

Agar pelaksanaan $\mathrm{P} 2 \mathrm{M}$ pada tahun berikutnya lebih efektif dan efisien maka sebelumnya dapat dilakukan analisis situasi di wilayah-wilayah lainnya yang sesuai dengan karakteristik program studi Pendidikan Khusus (PKh) dan sesuai juga dengan karakteristik sasaran, lebih baik lagi jika wilayah binaan yang akan dijadikan lokasi kegiatan P2M adalah yang terdekat dengan kampus/ lembaga FIP UNJ.

\section{PENUTUP}

\section{A. Kesimpulan}

Kesimpulan dari kegiatan ini berdampak positif pada kedua belah pihak yaitu Fakultas Ilmu Pendidikan sebagai Lembaga yang menyuelenggarakan P2M ini dengan pihak sekolah dasar (SD) di wilayah Kecamatan Sukamakmur. Permintaan untuk melanjutkan kegiatan ini secara berkesinambungan, menunjukkan kebermanfaatan kegiatan ini bagi mereka khususnya para guru SD yang selama ini menjalankan tugasnya dalam memberikan pembelajaran kepada $\mathrm{ABK}$ yang ada di sekolah masing-masing. Disamping membuat guru-guru memiliki wawasan dan pengetahuan serta keterampilan dalam melaksanakan pendidikan inklusif dan guru-guru juga sudah berubah mindset dalam memandang dan menyikapi kehadiran ABK di sekolahnya. 
DOI: https://doi.org/10.21009/sarwahita.151.03

P-ISSN: 0216-7484

E-ISSN: 2597-8926

3. melalui berbagai kegiatan pelatihan, workshop, lokakarya dan kegiatan Jakarta: PT Luxima Metro Media, 2013.

lainnya yang dapat mengembangan profesionalitas sebagai guru yang dapat memberikan layanan pendidikan dan pembelajaran kepada semua siswa.

4. Program studi Pendidikan Khusus (PKh) sebagai pelaksana P2M agar lebih meningkatkan kerjasama dengan berbagai pihak baik persekolahan maupun non persekolahan sehingga programprogram yang ada dapat tersosialisasikan serta dirasakan oleh masyarakat.

\section{DAFTAR PUSTAKA}

Asep Supena. Pengantar Pendidikan Anak Berkebutuhan Khusus. Jakarta: Lembaga Pengembangan Pendidikan UNJ, 2015.

Haenudin. Pendidikan Anak Berkebutuhan Khusus Tunarungu.

Lani Bunawan dan Cicilia Sulila Yuwati. Penguasaan Bahasa Anak Tunarungu. Jakarta: Yayasan Santi Rama, 2000.

Martini Jamaris. Kesulitan Belajar Perspektif, Asesmen, dan Penanggulangannya. Jakarta: Yayasan Penamas Murni, 2009.

Mohammad Efendi. Pengantar Psikopedagogik Anak Berkelainan. Jakarta: PT Bumi Aksara, 2009.

Mulyono Abdurrahman. Anak Berkesulitan Belajar Teori, Diagnosis, dan Remedinya. Jakarta: Rineka Cipta, 2012.

Murni Winarsih dkk. Program Khusus SLB Tunarungu Bina Persepsi Bunyi dan Irama. Jakarta: Pusat Kurikulum, 2010. 